\title{
Strategic Business Challenges in Cloud SYSTEMS
}

\author{
Dr. T. G. K. Vasista \\ Deanship of e-Transactions and Communications, King Saud University, Riyadh, KSA
}

\begin{abstract}
For the past few years, the evolution of cloud computing has been potentially becoming one of the major advances in the history of computing. But is cloud computing the saviour of business? Does it signal the demise of the corporate IT functionality entirely? However, if cloud computing has to achieve its potential, there is a need to have a clear understanding of various issues involved, both from the perspectives of the providers and the consumers related to the technology, management and business aspects. Objective of this research is to explore the strategic business, management and technical challenges existing in cloud systems. It is believed that adopting a methodology and suggesting a corresponding architectural framework would serve as a potential comprehensive conceptual tool, which shows path for mitigating challenges and hence effort are put in bringing in by mentioning a suitable methodology and its brief description. It concludes that International Business Machine Common Cloud Management Platform is one way to realize the combined features of various models such as Hub \& Spoke Model as a quality of Governance model; Gen-Spec Research Methodology design for semantic and quality research studies into one in the form of Reference Architecture. However in order to realize the full potential of the CustomerRespond-Adapt-Sense-Provider (conceptual) methodology for dealing with semantics, it is important to consider Internet of Things Architecture Reference Model where in the resources are translated into Services.
\end{abstract}

\section{KEYWORDS}

Cloud Business Challenges; Cloud Business Estimates; Cloud Computing; Cloud Deployment Models; IBM CCMP; Realizing CRASP methodology.

\section{INTRODUCTION}

For the past few years, the evolution of cloud computing has been potentially becoming one of the major advances in the history of computing. However, if cloud computing has to achieve its potential, there needs to have a clear understanding of the various issues involved, both from the perspectives of the providers and the consumers of the technology. While a lot of research is currently taking place in the technology itself, there is an equally urgent need for understanding the business and management related issues surrounding cloud computing and its probable mitigating solutions. Stakeholders in cloud computing include not only customers and providers but also enablers and regulators [1].

A cloud computing strategy is about enabling business agility. Cloud computing can improve flexibility, scalability and cost management. Businesses that are best able to realize the potential will be able to establish a cohesive business strategy as cloud computing can transform the organisation towards enterprise oriented functioning strategy with cost savings, optimized 
International Journal on Cloud Computing: Services and Architecture (IJCCSA), Vol. 5, No. 4, August 2015

business processes [2] and improved controls and offers to develop new revenue streams, mission critical service offerings and superior brand recognition [3].

\section{OBJECTIVE}

The Objective of this research effort is to explore the strategic business, management and technical challenges existing in cloud systems. It is believed that adopting a methodology and architectural framework would serve as a potential comprehensive conceptual tool, which shows path for mitigating challenges and hence effort are put in bringing in by mentioning a suitable methodology and its brief description.

\section{CLOUD DEFINITION AND CLASSIFICATION}

Cloud computing is an evolving paradigm. The NIST definition characterizes important aspects of cloud and is intended to serve as a means for broad comparisons of cloud services and deployment strategies. The services and deployment models defined from a simple taxonomy that is not intended to prescribe or constrain any particular deployment, services delivery or business operation. NIST defined cloud computing as a model for enabling ubiquitous, convenient, ondemand network access to shared pool of configurable computing resources (e.g., networks, servers, storage, applications and services) that can be rapidly provisioned and released with minimal management effort or service provider interaction. This cloud model is composed of five essential characteristics viz. (i) On-demand self-service (ii) Broad network access (iii) Resource Pooling (iv) Rapid elasticity (v) Measured Service; three service models viz. (i) Software as a Service (ii) Platform as a Service and (iii) Infrastructure as a Service; and four deployment models viz. (i) Private cloud (ii) Community cloud (iii) Public cloud (iv) Hybrid cloud [4].

Gartner defines cloud computing as "a style of computing where massively scalable IT-enabled capabilities are delivered 'as a service' to external customers using Internet technologies". A simple common-sense definition of cloud computing could be said as "anything but my assets"; "anything but a PC"; "anything but a main frame" and as a movement of assets from bought and implemented on-site to hosted, owned and provided by someone else has merit [5].

\section{Cloud Business Service Model Perspectives}

Adopting Cloud business model depicts a phenomenon of thinking on the decision making towards owning an asset versus renting it.

\begin{tabular}{|c|c|c|c|}
\hline Own it All & Lease It & Managed Hosting & Cloud Computing \\
\hline $\begin{array}{l}\text { Lowest Cost } \\
\text { Reduce agility } \\
\text { Slowest Provisioning } \\
\text { Times } \\
\text { No elasticity }\end{array}$ & $\begin{array}{l}\text { Higher Cost } \\
\text { Improved Agility } \\
\text { Slow Provisioning Times } \\
6+\text { months time scale } \\
\text { Little to no elasticity }\end{array}$ & $\begin{array}{l}\text { Higher Cost } \\
\text { Improved Agility } \\
\text { 24-hour } \\
\text { provisioning } \\
\text { Monthly timescales } \\
\text { Minimal elasticity }\end{array}$ & $\begin{array}{l}\text { Higher cost for static } \\
\text { Lower cost for } \\
\text { transient } \\
\text { Highest Agility } \\
\text { Immediate } \\
\text { Provisioning } \\
\text { High elasticity }\end{array}$ \\
\hline
\end{tabular}

Increasing Agility

Figure 1. A paradigm shift in conducting IT based business services [6] 
A business is a capital asset, though it is more heterogeneous than land and real estate. A business is durable and reproducible. It takes time to build. It has features to which a capital accumulation model is applicable. Economically speaking, while supply view talks in terms of capital investments, the demand view talks in terms of derivatives and adjustments and then there is a difference between the adjustment of the technological asset and that of real estate assets. One advantage with Cloud business model could be that the new discovery of knowledge can open up new information or further development possibilities so that the demand for the original asset value can keep increasing [7].

While SOA has been widely adopted, several organisations have yet to fully understand how it can be fully leveraged to truly bridge the gap between business and IT. From a business perspective, the focus has always been on maximizing value for the organisation. To accomplish this, the organisation relies on IT to strategically automate business operations [8]. Cloud computing as a business model describes a broad movement to treat IT services as a commodity with the ability to dynamically increase or decrease the capacity to match the usage needs [49]. Cloud computing presents a compelling business model by leveraging share infrastructure and economies of scale. It allows users to control the computing services they access, while sharing the investment in the underlying IT resources among consumers [9]. Cloud service models try to classify 'anything' that provider offer as a service (XaaS), where X means an arbitrary service (e.g. infrastructure, platform, software, storage...). A cloud service model represents a layered high-level abstraction of the main classes of services provided by the cloud computing model, and how these layers are connected to each other [10].

Cloud computing employs a service-driven business model. Cloud offer services that can be grouped into three categories: Software as a Service (SaaS), Platform as a Service (PaaS) and Infrastructure as a Service (IaaS). The definitions posted by [11] through techtarget.com web site are believed to provide value based knowledge content and are given here:

\subsection{Software as a Service}

Software as a Service (SaaS) is a software distribution model in which applications are hosted by vendor or service provider and made available to customers over a network, typically the Internet on demand. SaaS technologies support Web Services and Service Oriented Architecture and Ajax. SaaS is closely related to the Application Service Provider (ASP) and on demand computing software delivery models. While the ASP model follows the hosted application management model where a provider hosts commercially available software for customers and deliver it over the web, the Software On Demand model follow the software distribution model where provider gives customers network-based access to a single copy of an application created specifically for SaaS distribution. Customers get the advantage of getting freed from software administration, automatic and updates, patch management, version compatibility, global accessibility [11]. Examples of SaaS providers include Salesforce.com, Rackspace and SAP Business By Design [12].

\subsection{Platform as a Service}

Platform as a service (PaaS) is a cloud computing model that delivers applications over the Internet. In PaaS mode, a cloud delivers hardware and software tools (such as operating system support and software development frameworks) - usually those needed for application development making it available to its users in the form of a service. A PaaS provider hosts the hardware and software on its own infrastructure. As a result, PaaS frees users from having to install in-house hardware and software to develop or run a new application [11]. Examples of 
PaaS providers include Google App Engine, Microsoft Windows Azure and Force.com [12], VMware, CloudFoundary [6].

\subsection{Infrastructure as a Service}

Infrastructure as a Service (IaaS) is a form of cloud computing that provides virtualized computing resources over the Internet. In IaaS model, a third-party provider hosts hardware, software servers, storage and other infrastructure components on behalf of its users [11]. The cloud owner is also called IaaS provider [12]. IaaS providers also host users' applications and handle tasks including system maintenance, backup and resilience planning. IaaS model offers highly scalable resources that can be adjusted on-demand. This makes IaaS well-suited for temporary or experimental or workloads. IaaS environments are characterized by automating administrative tasks, dynamic scaling, desktop virtualization and policy-based services. This model promotes and works on pay per use @ hourly, weekly or monthly basis or it could be based on amount of virtual machine space used by the customers. The users' workload gets affected as a cascaded result when IaaS provider experiences the downtime [11]. Examples of IaaS providers include Amazon EC2, GoGrid and Flexiscale [12].

\section{CLOUD BUSINESS SERVICE DEPLOYMENT MODELS}

Four deployment models viz. Public cloud, private cloud, hybrid cloud [50] and community clod are listed by NIST [15]. Some of the corresponding commercial products are also mentioned here [51].

Table 1. Examples for the NIST Service and Deployment Models Matrix [6] [51]

\begin{tabular}{|c|c|c|c|}
\hline & SaaS & PaaS & Iaas \\
\hline Public Cloud & $\begin{array}{l}\text { Salesforce.com, } \\
\text { QuickBooks Online, } \\
\text { Office } 365\end{array}$ & $\begin{array}{l}\text { Google AppEngine, Microsfot } \\
\text { Azure, VMWare Cloud } \\
\text { Foundry.com }\end{array}$ & Amazon Ec2, Rackspace \\
\hline Private Cloud & & Apprenda, Stackato & $\begin{array}{l}\text { VMware, Hyper-V, } \\
\text { OpenStack, CloudStack }\end{array}$ \\
\hline Hybrid Cloud & & Custom Cloud Foundry & Custom, Rackspace \\
\hline $\begin{array}{l}\text { Community } \\
\text { Cloud }\end{array}$ & & $\begin{array}{l}\text { NYSE Capital Markets } \\
\text { Community Platform }\end{array}$ & $\begin{array}{l}\text { NYSE Capital Markets } \\
\text { Community Platform }\end{array}$ \\
\hline
\end{tabular}

\subsection{Public Cloud}

A cloud service provider makes applications and storage resources available to the generic public over the Internet on a pay-as-you-go basis [15]. The benefit of offering public cloud is for the purpose of eliminating the initial capital investment on infrastructure and shifting the risks associated with it to infrastructure providers. Lack of fine-grained control over data, network and security settings are some of the lacunas, which hampers the effectiveness in many business scenarios [12]. A growing number of companies are providing public cloud computing services such as Amazon, Google, Microsoft, Rackspace and GoGrid. These cloud providers offer a variety of option in pricing, performance and feature set [16]. For example, the Amazon Elastic Compute Cloud (EC2) allows users to rent virtual resources to run their own applications. EC2 
International Journal on Cloud Computing: Services and Architecture (IJCCSA), Vol. 5, No. 4, August 2015

runs within Amazon's network infrastructure and data centers. It allows customers to pay only for what they use with no minimum fee [15].

\subsection{Private Cloud}

A cloud infrastructure is operated solely for a single organisation's internal use by itself or run through outsourcing manner operating by third party [17]. Private Cloud refers to internal datacenters of a business or other organisation, not made available to general public [18]. A Private cloud offers the highest degree of control over performance, reliability and security [12]. But then up-front capital cost matters here. For example, Microft Azure enables customers to build the foundation for a private cloud infrastructure using Window Server and System Centre family of products with dynamic data centre tool kit [15].

\subsection{Community Cloud}

The cloud infrastructure is provisioned for exclusive use by a specific community of consumers from organisations that have shared concern. It may be owned, managed and operated by one or more of the organisations in the community, a third party or some combination of them and might exist on or off premises [4]. For example, the Google GovCloud provides the Los Angeles City Council with segregated data environment to store its applications and data that are accessible only to the city agencies [15].

\subsection{Hybrid Cloud}

The cloud infrastructure comprises two or more clouds among private, public or community [15]. For example, In India, by building a hybrid cloud bridge between Eucalyptus (Private Cloud) and Amazon Web Services (Public Cloud), customers gain the flexibility where to run workloads ensuring reliability, scalability, high availability of citizen centric e-Governance services [19].

\section{CHALLENGES IN CLOUD COMPUTING}

Some of the business, technical and management challenges are discussed as below:

\subsection{Business Challenges}

IT departments face several business challenges today, which include the following: High capital and operating expenditures and overhead caused by resource needs; low responsiveness to business needs due to complex IT operations; complex configuration difficulties; inefficient resource use in dedicated physical infrastructures, resource pool customization; resource scaling; longer deployment times; difficulty in integrating elements of cloud with other operating elements in the data centre that might demand higher operating expenses [20].

\subsection{Technical Challenges}

IT departments face several business challenges today, which include the following:

Data Lock-in; resource exhaustion; Unpredictability of performance; Data transfer; Bottlenecks; Bugs in large-scale distributed cloud systems [15]. 
International Journal on Cloud Computing: Services and Architecture (IJCCSA), Vol. 5, No. 4, August 2015

\subsection{Management Challenges}

A survey conducted by Accenture identified the following challenges [21] [15]:

Table 2. Cloud Management Challenges.

\begin{tabular}{|c|c|c|c|}
\hline Sl. No. & $\begin{array}{l}\text { Management } \\
\text { Challenge }\end{array}$ & Challenge Description & Mitigating Solution \\
\hline 1. & $\begin{array}{l}\text { Trust in data } \\
\text { security and } \\
\text { data privacy }\end{array}$ & $\begin{array}{l}\text { Safeguarding data (i.e. data security) and } \\
\text { privacy as the top most challenge }\end{array}$ & $\begin{array}{l}\text { Using domestic cloud } \\
\text { facilities; adopting new } \\
\text { security applications such } \\
\text { as encrypted file systems } \\
\text { and data-loss prevention } \\
\text { software; employing } \\
\text { hybrid clouds so that key } \\
\text { data is hosted and } \\
\text { managed internally and by } \\
\text { improving } \\
\text { governance. }\end{array}$ \\
\hline 2. & $\begin{array}{l}\text { Managing the } \\
\text { contract } \\
\text { relationship }\end{array}$ & $\begin{array}{l}\text { Customizing the compliance based cloud } \\
\text { standards to the specific needs to the client } \\
\text { might involve indirect breaches. Then } \\
\text { managing compensation to such breaches } \\
\text { of service level agreement becomes a } \\
\text { challenge. It could reflect as service } \\
\text { liability to the provider. As a result of } \\
\text { inadequate understanding of client's } \\
\text { enterprise level requirements, cloud } \\
\text { service providers show uncertainty in } \\
\text { service compliance, which matches client } \\
\text { requirements }\end{array}$ & 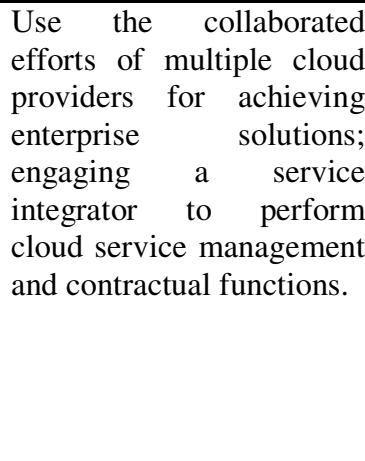 \\
\hline 3. & $\begin{array}{l}\text { Technology } \\
\text { and } \\
\text { Institutional } \\
\text { Lock in }\end{array}$ & $\begin{array}{l}\text { The usual practice of cloud business } \\
\text { vendors is to create a lock-in in terms of } \\
\text { providing specific branded technologies } \\
\text { and branded management consultancy } \\
\text { offers in order to encounter the business } \\
\text { competitors and to avoid the customer } \\
\text { switching play. }\end{array}$ & $\begin{array}{l}\text { However } \\
\text { specialist } \quad \text { services and } \\
\text { service } \\
\text { capabilities can help meet } \\
\text { these challenges }\end{array}$ \\
\hline 4. & $\begin{array}{l}\text { Organizational } \\
\text { inertia/Cultural } \\
\text { Resistance. }\end{array}$ & $\begin{array}{l}\text { Command and control over business } \\
\text { services kind of culture might create an } \\
\text { organisational inertia and cultural } \\
\text { resistance and hence become service } \\
\text { delivery bottlenecks in terms of time, } \\
\text { which might lead the cloud customer to } \\
\text { feel impatience and experience unsatisfied } \\
\text { services with respect to breaching service } \\
\text { level agreements. }\end{array}$ & \multirow{2}{*}{$\begin{array}{l}\text { Adopting transparency, } \\
\text { explicit declaration \& } \\
\text { evidence based formal } \\
\text { communication during } \\
\text { cloud service transaction } \\
\text { in addition to proper } \\
\text { planning, contracting and } \\
\text { management service, and } \\
\text { clarity in service level } \\
\text { agreement specifications } \\
\text { (through providing } \\
\text { suitable examples beside } \\
\text { every relevant } \\
\text { polymorphic terminology } \\
\text { used in service level } \\
\text { agreement) }\end{array}$} \\
\hline 5. & $\begin{array}{l}\text { Command and } \\
\text { Control } \\
\text { Strategy }\end{array}$ & $\begin{array}{l}\text { On one side command and control strategy } \\
\text { helps to achieve the desired outcomes, it } \\
\text { might give an opportunity to develop and } \\
\text { evolve the strategic level breaching } \\
\text { attitudes against the compliance to the } \\
\text { enterprise standards thus reflects Loss of } \\
\text { governance. }\end{array}$ & \\
\hline
\end{tabular}


International Journal on Cloud Computing: Services and Architecture (IJCCSA), Vol. 5, No. 4, August 2015

\section{Cloud Business Taxonomy as a Methodology Perspective}

Marxist-Leninist philosophy is the methodological foundation of all sciences, including medicine. Doctors of all specialties can be provided with a unique universal outlook and scientific methodology of knowledge. Knowing foundations of dialectic materialism is important for a generic doctor by taking guidance from the general laws of the development of nature and society, without which a doctor inevitably follows the path of prejudice that is often subjective and superficial concepts concerning individual phenomenon with which the doctor comes in contact in practical and scientific activity. It means, the conclusions for various problems studied and deductions based on the results of an extensive experiment or practical observation may bear a metaphysical or idealistic nature. So, the mission of any science including medicine should not be limited by the description of facts or their constancy alone. Knowledge consists of not of facts but of the results which stem from them. Dialectic materialism is a unique reliable weapon in deriving the perception of truth, scientific worker and doctors can systematize, develop and understand the regular bond between the individual facts and then correlated them. Through knowledge, a skilful utilization of the laws and categories of materialistic dialectics and their disclosure in the process of studying concrete science are of great importance on the activity of a doctor. It helps doctor to lie on the correct path for searches and investigations and also on the uniquely correct conclusions and deductions based on observations [22].

Taxonomy is an important phenomenon, which can be treated to be used as a methodology in providing a solution approach. A fundamental problem in many disciplines is the translation of classification of objects in a domain of interest into taxonomy. Developing taxonomy however is a complex process [23].

Zach defined Business Taxonomy as the "controlled vocabularies used to describe or characterize explicit concepts of information for the purpose of capture, manage and present" [24]. Taxonomy can thus best be described as a hierarchy created according to data internal to the items in that hierarchy [25]. The significance of having or defining taxonomy is not just for the sake of classification but also for the purpose facilitating the find-ability. Taxonomy is expected to reflect the key characteristics of Usability, reusability, intuitive and natural (e.g. the reflected output and manifested results of Google Search Engine) [24]. It is a tree that reflects the kind-of pattern.

For example, earlier methods of performing research included visiting library, searching the racks based on the keywords maintained through index cards, which are arranged either based on alphabetical manner or based on library accession number for the purpose of obtaining the desired content from the journal or books sources. Following this traditional process used to consume approximately $15 \%$ to $35 \%$ of the time for searching the information and $40 \%$ of the corporate users reported that they can find the information they need to do their jobs on their intranets [26].

The web has now become the primary source of information for many people. The web and especially major web search engines are essentially tools in the quest to locate online information for many people. Over $80 \%$ of web searchers use web search engines to locate online information or services [27].

It is evident that Google kind of search engines are used for the purpose of retrieving a high proportion of relevant, precise, good quality result set oriented and unique documents [28]. The library data bases do not allow to type long search phrases however might fetch the better quality relevant content from the cluster of relevant journal from relevant databases. But then subscription amount to such library research databases matter right? The preference of using Google kind of search engines over library databases is not only from the subscription based restriction point of view but also from the view point of capability of fetching the relevant content 
International Journal on Cloud Computing: Services and Architecture (IJCCSA), Vol. 5, No. 4, August 2015

based on typing the long search phrases [29]. It is evident from the research conducted by [30], why online search based research is highly significant for fetching the user-centric solutions for scholarly research as compared to do traditional way searching for them by physically accessing the library premises. This survey revealed the factors for users' preferences as: convenience $(84 \%)$; easier to use (87\%); faster (90\%); cost effective (71\%) and reliable $(63 \%)$ than traditional library access based searching. Bughin et al. (2011) [31] reported how internet technologies provide better search value benefits and its comparable economic value across few countries. Thus electronic resources save time in looking up for information and retrieving information based on providing relevant keyword search. So the summary finding of positive and negative sides of using such electronic resources among student community is mentioned in [32] document. ICT resource do not only save time in searching process of the content but also allow reduction in learning time [33].

Thus the even the Ph. D oriented academic researches which were planned to consume 5 years is now reduced to 3 years. But with the Google kind of Search Engines, web information dissemination and access has become easy and hence most of the universities across the world are mentioning that their $\mathrm{Ph}$. D programs can be completed by scheduling them to be with a minimum duration of completion to as low as two years (e.g. University of Lincoln; Ph. D. programs in Singapore; Trinity College, Dublin; University of Southampton etc.).

Taxonomy consists of three fundamental different parts: (i) Representation, which consists of nominal, reproducible statements; (ii) Ordering, which is a logical, verifiable science and (iii) Nomenclature, which is largely guided by practical application [34].

So, the normal Google search engines can now be enhanced with semantic search capabilities for fetching the context-driven result set based on the long keyword phrases given.

"Enterprise information access technologies are maturing and now offer better indexing, querying, presentation and drill-down of results. However, the real value of information access technologies is the upfront and ongoing efforts needed to establish effective taxonomies, to index and to classify content of all kinds in order to provide meaningful results [48]. By itself, the search function has limited value" [35]. The dynamic summaries feature of such semantic interface engines enhance search results by highlighting the evidence found during the classification process- that is - the preferred term, synonyms and related topics are highlighted in the search results $[35$, p. 12].

The recent manifestation and realization of such web based activities have been available in the form of web services to the user. Web services provide a new model of the web in which sites exchange dynamic information on demand. This kind of change is especially important for the ebusiness community, because it provides an opportunity to conduct business in a faster way and more efficiently. Indeed, the opportunity to manage supply chains dynamically to achieve the greatest advantage on the market is expected to create great value addition and increased productivity. However achieving automatic management of supply chain opens new challenges viz. (i) web services should locate other services that provide a solution to their problem (ii) services should interoperate to compose complex services [36]. Given, the dynamic environment in e-businesses, the power of being able to find webs services on the fly to create business processes is highly desirable. A key step in achieving this capability is the automated discovery of web services [47]. Though UDDI can enable to provide the dynamic capability of automated discovery of web services, however lack of semantics in the discovery process less effective even though the UDDI based interface can be used for keyword and taxonomy based searching. The key to semantic discovery of web services is to have semantics in the description itself and then using semantic matching algorithms to find the required services. Ontologies have been identified 
as the basis for semantic annotations that can be used for discovery [37]. It means while the use of taxonomy focuses on the controlled vocabulary that refers to its structural arrangement, the term knowledge base relates to both structure and data; then the term ontology is related to controlled vocabulary, relationships, process and methodology [38]. Thus structures, processes, relationships, methodology, data and interface constitute to contribute in fetching the mostly desired semantic information.

\section{CONCLUSION}

Thus Hub \& Spoke Model as a quality of Governance model [39]; Gen-Spec Research Methodology design for semantic and quality research studies [40] are then becoming prospective frameworks, which are having potential to explain the phenomenon of dialectic materialism concept, where dialectic materialism can be treated as a representation of object from which a number of dialects of objects can be instantiated (as forms based on taxonomy) for reflecting expressions with their corresponding specific bounded values.

For example CRASP management methodology developed by [41] in passing is based on the basic premise of strategic sense-and-respond paradigm can also be made applicable to real-world security with a modified view by including both customer perspective and provider perspective to the generic business model suggested by [42]. The objective of adopting CRASP methodology is to offer the satisfying features such as security, suability, flexibility (adaptability) and cost efficiency [43]. Underlying the trend toward this sense-and-respond technology is the identity of giving IT systems a deeper understanding of the semantics [44].

IBM CCMP (Common Cloud Management Platform) is one way to realize the combined features of all the above mentioned models into one in the form of Reference Architecture (i.e. CCMP RA). CCMP RA is a cross-IBM effort for an RA enabling cloud economics by optimizing resource and labour utilization, and delivering the foundational cloud management infrastructure for both private and public clouds [2] and in specific it could refer to IBM Reference Architecture for Business Management [45].

However in order to realize the full potential of the CRASP (conceptual) methodology [41] which includes the concept of dealing with semantics, it is important to consider IoT Architecture Reference Model where in the resources are translated into Services. Resources are software components that provide some functionality (it could associate with sensors and actuators). Services provide the link between the IoT aspects of a system and other, non-IoT specific parts of an information system, like e.g. various enterprise systems; IoT related services and non-IoT services can be orchestrated together in order to form a complete system [46].

\section{ACKNOWLEDGEMENTS}

The author would like to thank everyone at King Saud University, Riyadh, KSA.

\section{REFERENCES}

[1] Marston, S., Li, Z., Bandopadhyaya, S., Zhang, J., \& Ghalsasi, A. (2011). "Cloud computing the business perspective”. Decision Support Systems, 51(1), 176-189

[2] Breiter (2012). "IBM Cloud Computing Reference Architecture Overview". [Online] URL: https://www.academia.edu/6041679/IBM_Cloud_Computing_Reference_Architecture_Overview?log in=tgkvasista@gmail.com\&email_was_taken=true (Accessed on April, 5, 2015).

[3] PwC (2015). "Cloud computing is a strategic journey". [Online] URL: http://www.pwc.com/us/en/issues/cloud-computing/strategy.jhtml (Accessed on 29 January 2015). 
International Journal on Cloud Computing: Services and Architecture (IJCCSA), Vol. 5, No. 4, August 2015

[4] Mell, P., \& Grance, T. (2011). "The NIST definition of cloud computing”. Special Publication 800145, National Institute of Standards and Technology. U.S. Department of Commerce. [Online] URL: http://faculty.winthrop.edu/domanm/csci411/Handouts/NIST.pdf (Accessed on January 22, 2015).

[5] Plummer, D. C., Bittman, T. J., Austin, T., Clearley, D. W. \& Smith, D. M. (2008). "Cloud Computing: Defining and Describing an Emerging Phenomenon". [Online] URL: http://www.emory.edu/BUSINESS/readings/CloudComputing/Gartner_cloud_computing_defining.pd f (Accessed on January 22, 2015).

[6] Roberts, D. (2012). "What is Cloud Computing? - A Tutorial". [Online] URL: http://leverhawk.com/what-is-cloud-computing-tutorial-2012120519 (Accessed on January 22, 2015)

[7] Lai, L. W. C. \& Yu, B. T. (2006). "The Power of Supply and Demand: Thinking Tools and Case Studies for Students and Professionals". Reprinted with amendments, Hong Kong University press.

[8] Chen, R. (Undated). "Defining business services: SOA from a corporate perspective". [Online] URL: http://searchsoa.techtarget.com/tip/Defining-business-services-SOA-from-a-corporate-perspective (Accessed April, 5, 2015).

[9] Kundra, V. (2011). "Federal Cloud Computing Strategy". [Online] URL: http://www.mail.governmenttrainingcourses.net/pdfs/Federal-Cloud-Computing-Strategy1.pdf (Accessed April, 5, 2015).

[10] Hammadaqa, M. \& Tahvidari, L. (2012). "Cloud Computing Uncovered: A Research Landscape". In A. Hurson \& A. Menon (Eds.) Advances in Computers, Vol. 86, USA: Elsevier Publications.

[11] Rouse, M. (2014). "Infrastructure as a Service (IaaS)". [Online] URL: http://searchcloudcomputing.techtarget.com/definition/Infrastructure-as-a-Service-IaaS (Accessed on January 29, 2015).

[12] Zhang, Q., Cheng, L. \& Boutaba, R. (2010). "Cloud computing: state-of-the-art and research challenges". Journal of Internet Service Applications, 1, 7-18, Springer.

[13] Weinhardt, C., Anandasivam, A., Blau, B. Borissov, N., Meinl, T., Michalk, W. W. M. \& StoBer, J. (2009). "Cloud Computing - A Classification, Business Models and Research Directions", Business \& Information Systems Engineering, 5. 391-399

[14] Pallis, G. 92010). “Cloud Computing: The New Frontier of Internet Computing”. IEEE Internet Computing, IEEE Computer Society, September Issue. [Online] URL: http://cgi.di.uoa.gr/ ad/MDE556/Papers/palis-ic10.pdf (Accessed on January 22, 2015).

[15] Kuo, A. M. (2011). "Opportunities and Challenges of Cloud Computing to Improve Health Care Services". Journal of Medical Internet Research, 13 (3).

[16] Li, A., Yang, X., Kandula, S. \& Zhang, M. (2010). "CloudCmp: Comparing Public Cloud Providers". [Online] URL: http://www.cs.duke.edu/ xwy/publications/cloudcmp-imc10.pdf (Accessed on January 27, 2015)

[17] Grossman, R. L. (2009). “The Case for cloud computing. IT Professional”, 11(2), 23-27, IEEE.

[18] Armbrust, M., Fox, O., Griffith, R., Joseph, A. D., Katz, Y., Konwinski, A., Lee, G., Patterson, D. A., Rabkin, A., Stoica, I. \& Zaharia, M. (2009). "Above the clouds: A Berkeley view of cloud computing”. UC Berkeley Technical Report UCB/EECS-2009-28, EECS Department

[19] Eucalyptus Systems (2011). "Eucalyptus IaaS Platform Delivering Modern IT To Remote Villages in India". [Online] URL: https://www.eucalyptus.com/news/indias-national-informatics-centre-builds-egovernance-cloud-project-eucalyptus-cloud-software (Accessed April 5, 2015).

[20] CISCO (2010). "Virtualized Multi-Tenant Data centre solution for Infrastructure-as-a-Service". A white paper. [Online] URL: http://www.cisco.com/c/en/us/solutions/collateral/data-centervirtualization/data-center-virtualization/white_paper_c11-604559.pdf (Accessed on January 28, 2015).

[21] Willcocks, L., Venters, W. \& Whitley, E. A. (2011). "Meeting the challenges of cloud computing". Accenture, Outlook: Point of View, No. 1. [Online] URL: http://www.accenture.com/SiteCollectionDocuments/PDF/Accenture-Outlook-Meeting-thechallenges-of-cloud-computing.pdf (Accessed on 29 January 2015).

[22] U. S. Army (1966). "The Significance of Methodology of Dialectic Materialism for solution of Individual Epidemiological Problems". [Online] URL: http://www.dtic.mil/dtic/tr/fulltext/u2/648123.pdf (Accessed on January 29, 2015).

[23] Nickerson, R., Varshney, U. \& Muntermann, J. (2013). "A method for taxonomy development and its application in information systems". European Journal of Information Systems, 22, 336-359.

[24] Wahl, Zach (2014). "Enterprise Knowledge - Taxonomy Design Best Practices and Methodology". [Online] URL: http://www.slideshare.net/Enterprise-Knowledge/ek-taxo-designandimplementation (Accessed on January 27, 2015). 
International Journal on Cloud Computing: Services and Architecture (IJCCSA), Vol. 5, No. 4, August 2015

[25] van Rees, R. (2003). "Clarity in the usage of the terms ontology, taxonomy and classification". [Online] URL: http://reinout.vanrees.org/_downloads/2003_cib.pdf (Accessed on January 27, 2015).

[26] Feldman, S. (2004). "The high cost of not finding information". [Online] URL: http://www.kmworld.com/Articles/Editorial/Features/The-high-cost-of-not-finding-information9534.aspx (Accessed April 5, 2015).

[27] Jensen, B. J. \& S. A., (2006). "How are we searching the World Wide Web? A comparison of nine search engine transaction logs". Information Processing \& Management, 42(1), 248-263.

[28] Brophy, J. \& Bawden, D. (2005). "Is Google enough? Comparison of an internet search engine with academic library resources”. Aslib Proceedings. 57 (6), 499-512.

[29] Perez, J. C. (2009). "Google Rolls out Semantic Search Capabilities". [Online] URL: http://www.pcworld.com/article/161869/google_intros_semantic_search.html (Accessed on January 27, 2009).

[30] Sadesh, T. (2007). "User-Centric Solutions for Scholarly Research in the Library". Liber Quarterly, 17(3/4), ISSN 1435-5205.

[31] Bughin, J., Corb, L., Manyika, J., Nottebohm, O., Chui, M, Barbat, B. M. \& Said, R. (2011). "The impact of Internet technologies: Search". McKinesy \& Company.

[32] Epic (2001). "The use of electronic resources among undergraduate and graduate students". [Online] URL: http://www.epic.columbia.edu/eval/find03.html (Accessed on January 27, 2015).

[33] Eng, T. S. (2005). "The impact of ICT on learning: A review of research". International Education Journal, 6(5), 635-650.

[34] Hoog, G. S. (1981). "Methodology of Taxonomy”. Taxon, 30(4), 779-783. International Association for Plant Taxonomy.

[35] SmartLogic (2011). "Semaphore Overview: A Smartlogic" White Paper. [Online] URL: http://www.barbador.com/assets/kb-smartlogic/Semaphore-White-Paper.pdf (Accessed on 27 January, 2015)

[36] Paolucci, M., Kawamura, T., Payne, T. R. \& Sycara, K. (2002). "Semantic Matching of Web Services Capabilities". [Online] URL: http://eprints.soton.ac.uk/257606/1/ISWC2002-Matchmaker.pdf (Accessed on 27 January 2015).

[37] Sivashanmugam, K., Verma, K., Sheth, A. \& Miller, J. (Undated). "Adding Semantics to web services standards". [Online] URL: http://knoesis.wright.edu/library/download/SemanticWSOld.pdf (Accessed 27 January, 2015).

[38] Ideaeng (2014). "What's the difference between taxonomies and Ontologies? - Ask Dr. Search". [Online] URL:http://www.ideaeng.com/taxonomies-ontologies-0602 (Accessed on 27, Jan, 2015).

[39] Vasista, T. G. K. (2015). :Theoretical framework of quality of governance". A working paper at King Saud University, Riyadh, Saudi Arabia. [Online] URL: https://kingsaud.academia.edu/TgkVasista/Papers (Accessed on 29 January 2015)

[40] Vasista, T. G. K. (2011). "Gen-spec research methodology design for semantic and quality research studies". In Proceedings of First International Conference on Emerging Research Paradigms in Business and Social Sciences, 22-24 November, Middle Sex University, Dubai, UAE.

[41] Alsudairy, M. A. T. \& Vasista, T. G. K. (2014). "CRASP-a strategic methodology perspective for sustainable value chain management,". In Proceedings of the 23rd IBIMA Conference, Valencia, Spain, May 13-15.

[42] Donovang-Kuhlisch, M. (2006). "Security and Privacy within an Intelligent Sensor Grid". In 11th International Commands and Control Research and Technology Symposium. September 26-28, Cambridge, USA.

[43] Andrade, A. (2011). "Strong Mobile Authentication in Single Sign-On Systems". Master Thesis, Department of Computer Science and Engineering. Aalto University, Esbo, Finland.

[44] IBM-SecSol (2008). "IBM Security Technology Outlook: An outlook on emerging security technology trends". A white [Online] URL: http://www.guruonline.tv/services/viewfile.aspx?type=1000\&DocumentId=154823 (Accessed on March 25, 2014).

[45] IBM RedbooksDoc (2009). “Define BPM Reference Architecture”. [Online] URL: ftp://www.redbooks.ibm.com/redbooks/REDP4543/ArchitectureGuide.pdf

[46] IoT-A-257521 (2013). "Internet of Things -Architecture- IoT-A: Deliverable D1.5"- Final architectural reference model for IoT v3.0. [Online] URL: http://iotforum.org/wpcontent/uploads/2014/09/D1.5-20130715-VERYFINAL.pdf (Accessed April 5, 2015)

[47] Helal, A., Mokhtari, M \& Abdulrazak, B. (2008). The Engineering Handbook of Smart Technology of Aging, Disability and Independence, USA: Wiley Publishing. 
International Journal on Cloud Computing: Services and Architecture (IJCCSA), Vol. 5, No. 4, August 2015

[48] Swoyer, S. (2006). "How Enterprise Search Changes Everything - Especially Expectations". [Online] URL: $\quad$ https://esj.com/articles/2006/03/22/how-enterprise-search-changes-everythingespeciallyexpectations.aspx (Accessed July 30, 2015)

[49] Zillman, M. P. (2015). Grid, Distributed and Cloud Computing Resources Primer. [Online] URL: http://whitepapers.virtualprivatelibrary.net/Cloud_Computing_Primer.pdf (Accessed on July 30, 2015)

[50] Chaudhary, J. (2014). Network Security: Cloud Computing. International Journal of Engineering and Computer Science. 3(7), 7355-7363.

[51] Sardana, B. S. (2011). Term Paper for E-Business Technology. [Online] URL: http://webuser.hsfurtwangen.de/ heindl/ebte-2010ws-Cloud\%20Computing\%20Final\%20Term\%20paper.pdf (Accessed on August 4, 2015)

\section{AUTHORS}

Dr. TGK Vasista is currently working as Faculty of e-Transactions and Communications at King Saud University, Riyadh, KSA. He obtained a Doctorate in Information Technology, Commonwealth of Dominica, a Post-Graduate Diploma in E-Governance from University of Mysore, India, a Master of Business Admonition (e-Business) from Wevac University, USA, and Master of Engineering in Computer Aided Design from University of Roorkee (Now called IIT-Roorkee), India. He has former experiences in Research in the fields of e-Business and e-Governance in Saudi Arabia, as a senior Lecturer/Asst. Professor in academic field in the area of Systems and IT, E-Business

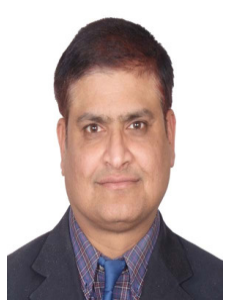
and E-Governance in India and Libya and as programmer analyst in the IT industry in India and USA. 